Documentación de las Ciencias de la Información ISSN: 0210-4210

http://dx.doi.org/10.5209/DCIN.61472

\title{
La Gestión de contenidos audiovisuales en Canal Extremadura TV
}

\author{
Verónica Vazquez de Ágredos Jaén ${ }^{1}$
}

Recibido: 16 de septiembre de 2018 / Aceptado: 22 de octubre de 2018

Resumen. La tendencia que tienen las televisiones a digitalizar los archivos audiovisuales, producirá cambios importantes en los Departamentos de Documentación. En este artículo se presenta cómo se gestionan las imágenes digitales en un medio de comunicación, la televisión de Canal Extremadura. Palabras clave: Digitalización de archivos; medios de comunicación, Documentación audiovisual.

\section{[en] Management of audiovisual contents at Canal Extremadura TV}

\begin{abstract}
The tendency of televisions to digitize audiovisual archives will produce important changes in the Documentation Departments. This article presents how digital images are managed in a communication medium, the television of Canal Extremadura.
\end{abstract}

Key words: Archives digitalization; mass media; audiovisual documentation

Sumario: 1. Introducción. 2. El sistema digital en Canal Extremadura TV. 3. Nomenclatura de Almacenamientos. 4. Recuperación de los Documentos con el sistema digital. 5. Conclusiones.

Cómo citar. Vazquez de Ágredos Jaén, V. (2018). La Gestión de contenidos audiovisuales En Canal Extremadura TV, en Documentación de las Ciencias de la Información 41, 61-71.

\section{Introducción}

Los tiempos cambian y con ellos los medios de comunicación, y la Documentación audiovisual va cobrando gran importancia en nuestro país debido al gran desarrollo tecnológico experimentado por el sector audiovisual. En pleno siglo XXI los servicios de documentación de prensa, radio y televisión trabajan con un sistema que nada tiene que ver con el de hace años. Tiempo atrás, parecía impensable almacenar imágenes en un sistema informatizado. Hoy ese reto no sólo es posible, sino que se ha extendido y se ha consolidado en todo el mundo.

Canal Extremadura televisión, medio de comunicación de reciente creación, se ha sumado al panorama periodístico regional, con una decidida apuesta por la digitali-

Responsable del Departamento de Documentación de Canal Extremadura veronica.vazquez@canalextremadura.es 
zación de su archivo audiovisual. El servicio, que incluye la descripción de toda la información grabada para hacerla accesible después, será el eje central de este estudio.

En treinta / treinta cinco años hemos pasado de tener dos cadenas de Televisión, a contar con una abundante oferta audiovisual, desde las autonómicas, las privadas, pasando por las locales, los canales de Televisión digitales, por cable y por satélite, y recientemente, el desarrollo de la Televisión interactiva, donde el telespectador adquiere un rol activo, capaz de escoger aquello que le interese; con todo ello surge la necesidad de ir digitalizando todo los archivos audiovisuales de estas cadenas de televisión, donde se involucran distintos departamentos en un arduo trabajo.

Las nuevas tecnologías electrónicas aparecen como el medio idóneo para procesar, almacenar, recuperar, de forma digital todo el volumen de información; para almacenar, recuperar y comunicar dicha información. Permite el procesamiento conjunto de material escrito, sonoro o visual, es decir, de Documentación Multimedia ante la integración de la informática y lo audiovisual- que puede ser entendida como:

La obtención de información documentada- de nuevo conocimiento- mediante la integración de diversos sistemas audiovisuales (televisión, video, cine, incluso fotografía en el sentido de imagen susceptible de ser digitalizada y transformada acoplándosele sonido) con la informática, de forma interactiva.

La digitalización de archivos, fotografías, imágenes etc., han originado nuevas connotaciones al concepto de documento y al proceso documental en su conjunto dado que posibilita tener la información original desde cualquier punto. Pero a pesar de utilizar nuevas tecnologías, se precisa de una organización y estructuración de la información. Esto lo facilitan los nuevos modos de trabajo como los Sistemas de Gestión de Bases de Datos (SGBD) o los Sistemas Hipertextuales. Todo ello repercutirá no sólo en el almacenamiento sino también en la distribución, conscientes de las desventajas que suponían los sistemas anteriores.

Tradicionalmente, las cadenas de televisión han trabajado siempre con el formato de cinta, tipo betacam, (Cintas 1/2 pulgada de hasta $124 \mathrm{~min}$ ) dvcpro (Cinta de 1/4 de pulgada de hasta $123 \mathrm{~min}$ ) etc., las cuales han sufrido una importante transformación afectando al archivo audiovisual, en primer lugar, por la obsolescencia de muchos formatos que van cambiando con los años y que imposibilitan trabajar con ellos, y por otra parte, por el esfuerzo del profesional de documentación para la digitalización de su archivo audiovisual. En suma, ha supuesto una revolución en la forma de trabajar en los distintos departamentos.

La digitalización es un proceso tecnológico donde datos, gráficos, sonidos e imágenes se transforman en bits, codificando y comprimiendo las señales originales. Esto permite la convergencia de contenidos y plataformas, ya que ahora podrán ser retransmitidas a través de soportes comunes, convergiendo a través de múltiples tipos de redes, sean ondas hertzianas, cables ópticos o emisiones satelitales. Cuando la digitalización es aplicada en tecnologías de información y comunicación que utilizan el espectro radioeléctrico para su propagación, la compresión produce una optimización del uso de este recurso limitado. Por ejemplo, en la Televisión Digital Terrestre (TDT) la compresión digital permite que, para recibir la misma señal de TV analógica que actualmente vemos en nuestros receptores se utilice menos ancho de banda". (Gómez Germano, 2007) 


\section{El sistema digital en Canal Extremadura Tv}

Hasta ahora, los medios de comunicación trabajaban con herramientas poco llevaderas en el día a día para contar con una mayor rapidez, sin embargo, hoy en día se utilizan software enfocados a los flujos de trabajo sin cintas, con clientes en todo el mundo, desde televisiones a radios, convirtiéndose en un referente de la industria audiovisual, haciendo que el flujo de trabajo en las televisiones sea rápido y práctico sin tener nada que ver con la pesada cinta que cuando ya se conseguía, podía ser que no fuera el material deseado. Con el sistema digital el usuario accede a la imagen rápidamente y puede decidir en el acto si quiere o no la imagen hallada.

Existen diversos programas para la gestión del material audiovisual. Canal Extremadura televisión utiliza el programa Dalet, que mediante un robot, hace que lleve la información a cada puesto de redacción o documentación, usuarios frecuentes en utilizar dicho material.

Para digitalizar el fondo audiovisual de cualquier cadena de televisión, el primer paso es visionar cada cinta, y saber que contenido tiene, y posteriormente se tendrá que hacer una selección, del fondo, puesto que no se podrá digitalizar entero, por coste, tiempo y esfuerzo.

El siguiente paso sería digitalizar el contenido, que se haya seleccionado del fondo del archivo documental y a través del proceso de ingesta digitalizarlo con el programa Dalet utilizado en Canal Extremadura Televisión.

En la figura1, explicamos como se gestiona el material audiovisual a través de las plataformas creadas para una televisión. Podemos observar con claridad que existen dos sistemas, distribuidos por servidores. El sistema principal tiene 12 servidores puesto que es utilizado por un mayor número de usuarios y el sistema archivo tiene 3 servidores.

En el área de usuario se encuentran ubicados los usuarios finales de la plataforma. Clientes para redacción, edición, PlayOut de emisión, Ingestas desde las cámaras, Documentalistas etc.

En la granja de servidores de la plataforma de digitalización se encuentra los servidores de aplicaciones. En ellos estarán distribuidos los servicios específicos de cada función, como puede ser la gestión de la base de datos principal donde se gestiona desde el acceso de usuarios hasta cualquier movimiento de ítems en toda la plataforma, ya sean videos, textos o escaletas.

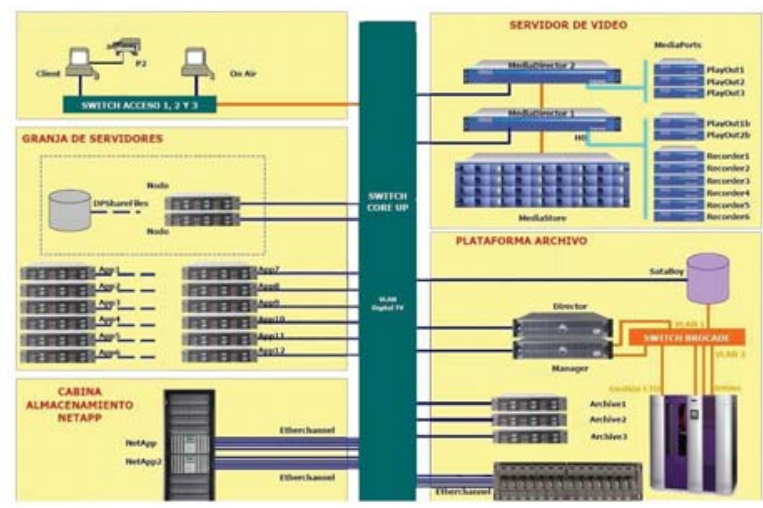

Ilustración 1. Elaboración Propia 
Existen otros servicios muy importantes, como gestión y sincronización de toda la granja de servidores, u otros más específicos de aplicaciones, como renderización de videos, ingestas, transferencias entre almacenamientos, purga automática de ítems, control de los clientes, PlayOut de la emisión, etc.

La cabina de almacenamiento para la producción de media es uno de los elementos más importantes. En ella se almacenarán todos los videos y textos de la plataforma de digitalización. También es importante mencionar que el almacenamiento para los videos que van a ser emitidos o han sido simplemente ingestados, se denomina Omneon. Es muy importante una buena gestión del almacenamiento, ya que debido al alto tamaño de la media puede llegar a colapsarse rápidamente el sistema.

Los videos documentados con su análisis documental (añadiendo la metadata a los videos) deben ser almacenados en el archivo profundo. Para optimizar el acceso al archivo, es recomendable colocar un almacenamiento de disco que de forma temporal almacene todo lo enviado al archivo profundo. El video en este caché tendrá un tiempo de vida previamente establecido, ya que se encuentran en un sistema de almacenamiento con una determinada capacidad y si se llenara las distintas emisiones de la programación podría verse afectada. No quiere decir que estos videos si se eliminan de este sistema se perderían, sino estos videos se almacenarían en el archivo profundo como anteriormente hemos dicho.

Para conectar la plataforma de digitalización y el archivo profundo, existe un robot de cinta capaz de gestionar miles de terabytes de video, y este se gestiona a través de un sistema que estará conectado a través de fibra óptica a la librería de cintas.

Canal Extremadura comienza a trabajar en 2006, con los sistemas de almacenamientos, colocando como archivo de disco intermedio una cabina de almacenamiento, y como gestor de contenido de la librería o robor de cinta del sistema, se colocaba otra cabina de almacenamiento distinta. En la siguiente figura veremos este proceso.

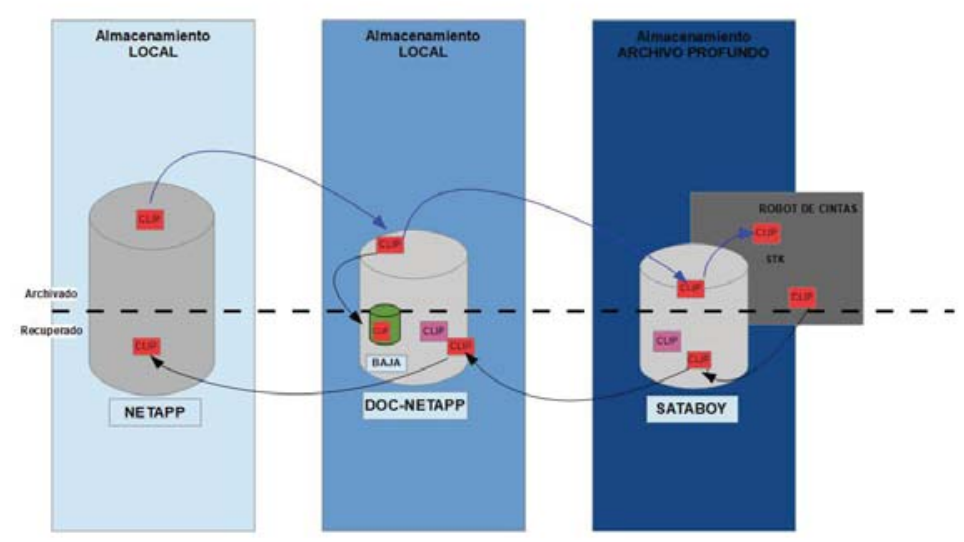

Ilustración 2. Elaboración Propia

En la figura, anterior, explicamos el proceso de digitalización en Canal Extremadura Televisión. Viene dividida en tres partes "NETAPP", "DOC-NETAPP" Y SATABOY; estas partes son cabinas de almacenamiento donde permanecen los videos. Cuando transferimos videos desde el sistema principal al sistema de Archivo (Archivado), lo que hace el sistema es mantener una copia de alta calidad en Doc-Netapp y 
otra en el Archivo profundo. A continuación, se mantiene una copia en baja calidad, en el sistema y almacenamiento local Doc-Netaap, para que se pueda trabajar con facilidad y no se colapsen los equipos. En el momento que el Documentalista le da para archivar al video o imagen, se mantienen las copias en los sistemas de almacenamiento local, y envía el video definitivamente a archivo profundo para su posterior recuperación.

El proceso inverso; es decir, transferir desde el sistema archivo al sistema principal (Recuperado), a la hora de trasferir los videos afecta de dos formas distinta puesto que al guardarse una copia en alta calidad en Doc-netapp, los videos que se encuentren en éste solamente tendríamos que copiarlo al sistema principal. Mientras los videos que se encuentran en Diva habría que extraerlos y se repetiría el proceso anteriormente explicado, por lo que tardaría mucho más en llegar al sistema principal. Las copias de alta calidad de Doc-netapp tienen un periodo de vida determinado, porque tanto Doc-nettap como Nettap tienen un espacio más pequeño, y de ahí a que se mantengan sólo por un tiempo. Este tiempo determinado en el que permanecen los videos en el sistema de almacenamiento de Doc-netapp lo hace de forma automática aunque siguiendo un criterio de purga; es decir, la purga automática lo hará de los videos que menos se utiliza, por tanto los videos más utilizados, se van a mantener en Doc-netapp, mientras que los videos menos utilizados, se eliminarán de Doc-nettap y se enviarán definitivamente al archivo profundo. Si Alguna vez sacamos el video de Diva este permanecerá en Doc-netapp hasta su tiempo de purga.

En la actualidad, desde 2017, este esquema ha cambiado; la principal causa es que anteriormente, los documentalistas trabajaban con una versión del programa distinta al de redactores, montadores, editores etc.,

Anteriormente se trabajaba con dos cabinas de almacenamientos locales, uno para los documentalistas y otra para el resto, por tanto, ya no hay que transferir de un sistema a otro y la fluidez de intercambio de imágenes es mucho más rápida y eficaz.

También se ha incluido otro sistema de Almacenamiento remoto, que anteriormente no existía, este se ha colocado para transferir videos al exterior, así manteniendo el formato digital, hacia Delegaciones o Productoras, que usan el mismo formato.

Ahora los sistemas de almacenamiento Netapp y Doc-Netapp se llama Netapp-Online y Netapp-Archive respectivamente, nos preguntaremos, el por qué de este cambio de nombres, y es porque estos almacenamientos, ha convivido un tiempo juntos hasta la completa integración en el sistema.

Se sigue trabajando con transferencias, como con el sistema antiguo, pero éstas son mucho más rápidas y colapsan menos el sistema, puesto que estas transferencias solamente se harán cuando el video se vincule al sistema de almacenamiento Remoto; podemos decir que sería otra particularidad del nuevo modelo de trabajo, y es que trabajando con vínculos, el sistema comprobará si en el almacenamiento remoto se encuentra el video que hemos vinculado, siguiendo siempre las reglas de migración impuestas por el departamento de informática, y afectará o no una transferencia que puede ser de tipo copia o conversión. Todo esto en función del almacenamiento remoto al que estemos vinculando. Por tanto, podemos decir que es una particularidad muy importante, del nuevo modelo de trabajo, puesto que hace que el sistema no se colapse con tanta facilidad y las imágenes en muchas ocasiones, sobre todo para el personal que trabaje en Canal Extremadura, puedan tenerlas al instante. 


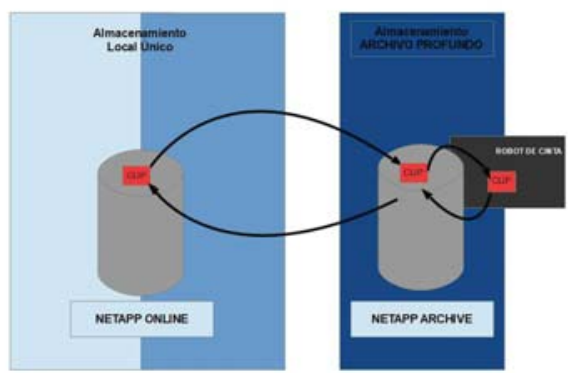

Ilustración 3 Elaboración Propia

\section{Nomenclatura de Almacenamientos}

Todo este proceso de digitalización lleva a que el video pase por una serie de estados; para que todo usuario pueda trabajar y saber si un video puede ser usado para un futuro proyecto de trabajo, este usuario debe saber en qué estado y sistema de almacenamiento se encuentra el video.

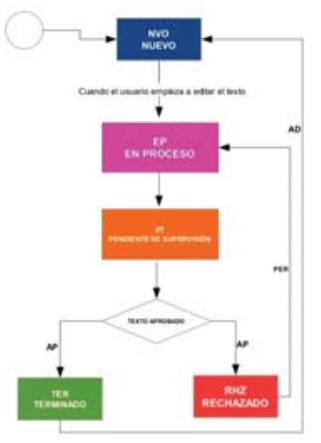

Ilustración 4 Elaboración Propia

Estados video para emitirse

User Group

$\mathrm{AD}=$ Administradores

$\mathrm{AP}=$ Aprobadores

$\mathrm{PER}=$ Usuarios

En la figura anterior, mostramos desde que se inicia el proyecto de una noticia, el video pasa por diferentes estados, Nuevo (NVO), En proceso (EP), Pendiente de supervisión (PT); Terminado (TER), Rechazado (RHZ); todo usuario debe conocer el estado del video puesto que nos indica si finalmente puede estar listo para emisión. 


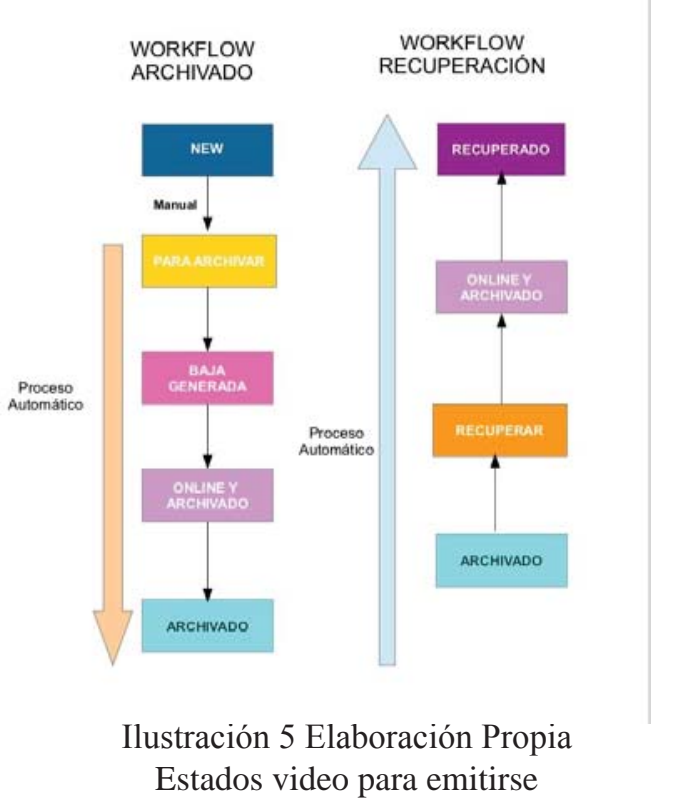

En la figura observamos que hay varios estados por los que pasa un video, los cuales indican la fase en el que se encuentra dicho video en el sistema, estos estados son:

Nuevo: Es el estado en el que todavía el video no ha sido manipulado (primer estado); es decir, estado en el que la base documental detecta el video a través un código que señala que la imagen ha llegado al sistema.

Para Archivar. Es el estado de conversión del video a baja calidad, para permitir el visionado del video sin afectar el ancho de banda de la red.

Archivado. Este estado nos indica que el video se encuentra archivado en Diva; es decir, se encuentra almacenado definitivamente en alta calidad en el sistema de Archivo o robot de cintas. El video se mantendrá en local durante un tiempo. Cuando pase el tiempo de purga se eliminará de local y permanecerá solamente en Diva

Recuperado. Estado que nos indica que el video se ha extraído de Diva (ARCHIVO PROFUNDO) y se encuentra disponible en el sistema principal.

Todos estos estados pueden verse su porcentaje de renderización en la se ventana de "job monitor". El proceso de renderización es aquel que hace que el video quede almacenado correctamente en el sistema. Una vez que el documentalista extrae la imagen para prestarla se repiten los estados Retrieval in progres y Archivado. Para finalizar decir que el formato de emisión de Canal Extremadura es el SD 720x576, sistema con una resolución de 500 líneas horizontales PAL, y se ha utilizado siempre, tanto cuando se emitía en 4.3 como en 16.9. Este formato es el formato estándar, que es el que utiliza la mayoría de las televisiones, aunque cada vez más se esté utilizando cada vez más el formato de HD (alta definición). 


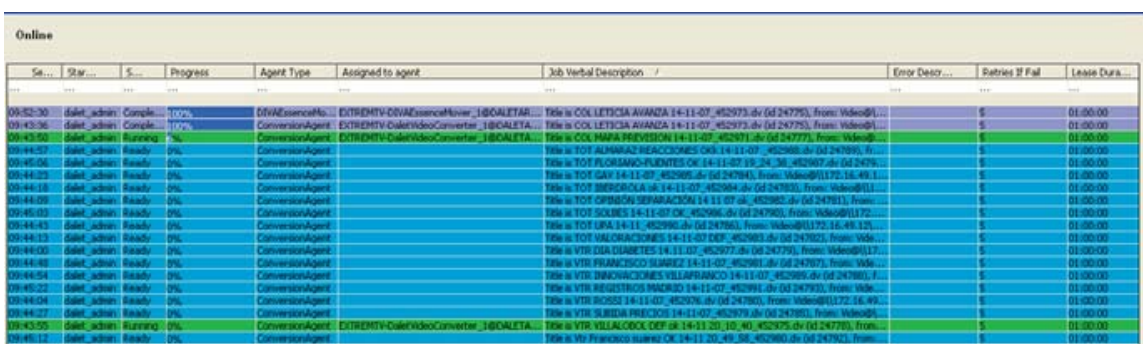

\begin{tabular}{|l|l|}
\hline $100 \%$ & DIVAEssenceMo... Title is COL LETICIA AVANZA 14-11-07_452973.dv (id \\
\hline $100 \%$ & ConversionAgent Title is COL LETICIA AVANZA 14-11-07_452973.dv (id \\
\hline $3 \%$ & ConversionAgent Title is COL MAPA PREVISION 14-11-07_452971.dv (id \\
\hline
\end{tabular}

Ilustración 6. elaboración propia

\section{Recuperación de los Documentos con el sistema digital}

Cuando hay que buscar información acerca de un asunto o tema a tratar en los servicios informativos o programas de televisión, es necesario emplear una estrategia de búsqueda para que el resultado de la búsqueda sea exitoso: más rápido, con la mejor, la mayor información y con la información válida (objetiva, significativa, pertinente, confiable, actual o vigente).

Las búsquedas pueden hacerse a través de operadores o expresiones booleanas, que permiten combinar los términos de búsqueda de acuerdo con las necesidades del usuario de las cadenas de televisión, pero más allá de explicar las estrategias de búsquedas de cualquier centro de documentación, nos centraremos en una vez realizada esa búsqueda cómo se debe de actuar con la información hallada.

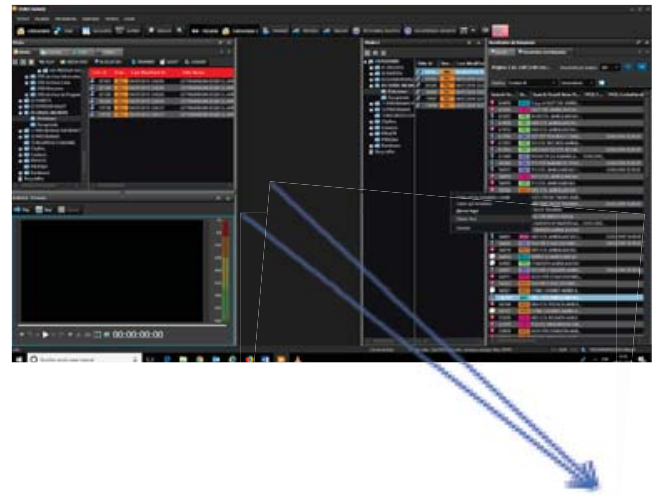

Estados

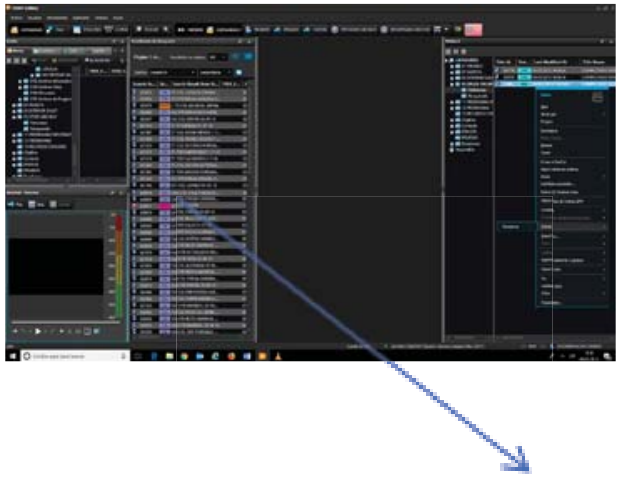

Daremos a recuperar

Ilustración 7. Elaboración Propia

En la figura podemos ver los estados anteriormente explicados, y observamos que en la búsqueda realizada ha salido varios resultados con distintos estados, que 
tienen ellos con distintos colores, que nos indican y advierten qué debemos hacer en cada caso.

Si el archivo deseado se encuentra en estado ARC, nos indica que se encuentra en archivo profundo y que no está en el sistema principal, por tanto el usuario deberá enlazarlo a la carpeta peticiones para que los documentalistas puedan recuperarlo, de esta recuperación se encarga el departamento de Documentación, y serán los documentalistas quienes recuperen el video.

En algunas ocasiones nos podemos encontrar con videos que no se encuentren en "Local: Video" ó "Local: NearOnline" en estado Online como podemos mostrar en la siguiente figura

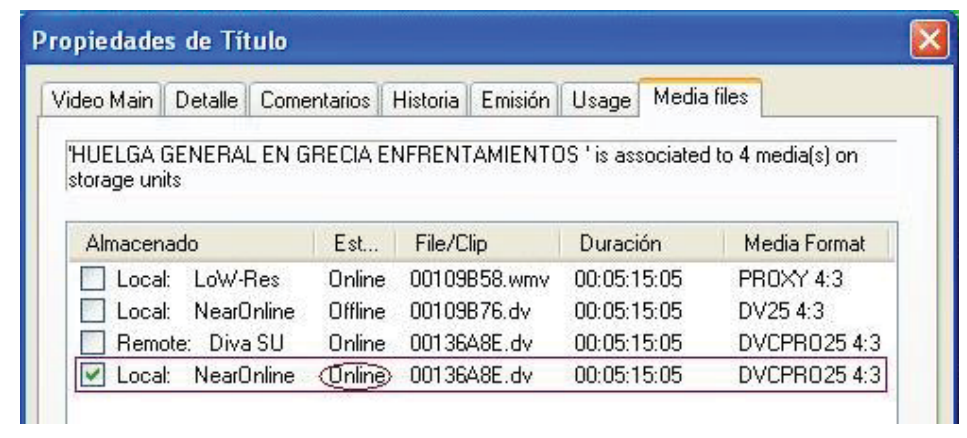

Ilustración 8. Elaboración Propia

Los Videos que no se encuentre en Online no se podrán utilizar para la edición de otros videos, esto se averigua haciendo clic con el botón derecho sobre el video y verificando las propiedades de la media, y con esto podremos saber si conseguiremos trabajar con el video o no.

En el caso que se intente trabajar con dichos videos con NearOnline en off se nos presentarán los siguientes casos:

a) En el caso de hacer clic con botón derecho sobre el video con la que se intenta trabajar y seleccionáis propiedades. Donde seleccionaremos de nuevo Media files y "Local: NearOnline" y en "Verificar propiedades" de la media vemos que en lugar de mostrarse Online como ocurre en la anterior figura, se muestra en estado Offline. Se deberá solicitar dicho video de nuevo a Documentación.

b) al abrir la EDL nos muestra el siguiente mensaje que mostramos en la figura siguiente, esto, es señal de que se solicitó hace demasiado tiempo a Documentación una o varias piezas que hemos utilizado en nuestra EDL y no guardamos una copia para su uso en dv en nuestra carpeta personal. En este caso, debemos seleccionar

\section{Conclusiones}

La digitalización de los archivos audiovisuales permite mejorar el trabajo tanto de los documentalistas como de los periodistas. 
Existen una seria de ventajas del sistema digital frente al analógico como son , mayor rapidez, al estar en un sistema informatizado no se tiene que acudir al archivo ni desplazarnos de nuestro sitio con un solo clip, el redactor tiene las imágenes; fácil de manejar, antes con las cintas si eran muy grandes como por ejemplo las cintas betacam, cuando había que llevar muchas a la vez era muy fácil que se cayeran al suelo con la consecuencia que después las imágenes se encontraran en mal estado; ahorro de tiempo relacionada con la rapidez, ya que al no tenerse que desplazar al archivo de cintas, se ahorra tiempo, pero no solo en el desplazamiento sino también a la hora de hacer los compactados, ya no se graban las imágenes en una cinta a tiempo real; es decir, se ahorra tiempo en el trabajo diario; y por último evitar el deterioro de las imágenes, en el sistema digital ya no se prestan a los redactores originales, siempre se manda una copia idéntica, desde el sistema archivo al sistema principal, con lo que evitamos que el redactor pueda manipular la imagen original y no dañarla, en muchas ocasiones cuando se trabaja con el sistema analógico, el redactor infinidades de veces quitaba sin intención ninguna la seguridad del original y grababa encima de ella, con lo que la imagen se pierde definitivamente.

Con el sistema digital hay un aumento de productividad al facilitar acceso a los archivos de la cadena; y finalmente los archivos pueden guardarse con un nivel de seguridad mayor, cada usuario puede tener su contraseña y se limita el acceso a los archivos para tener un mejor control de los datos.

\section{Bibliografía}

Agirrazaldegi Berriozabal, Teresa. El uso de la Documentación audiovisual en los programas informativos diarios de televisión. [Bilbao]: Servicio de Publicaciones de la Universidad del País Vasco, 1996.

Codina, Lluís. La Documentación en los medios de comunicación: situación actual y perspectivas de futuro. En: I Congreso Universitario de Ciencias de la Documentación: Teoría, Historia y Metodología de la Documentación en España (1975-2000), Madrid, 14-17 de noviembre de 2000. Madrid: Universidad Complutense, Facultad de Ciencias de la Información, 2000.

Codina, Lluís. Sistemas automáticos de recuperación de información textual. En: Aplicaciones lingüísticas de la Informática. Santiago de Compostela: Tórculo, 1994.

Galdón López, G. Principios operativos el servicio de documentación de prensa: funciones y métodos. Barcelona: Mitre, 1986.

García Gutiérra, A.; Lucas Fernández, Ricardo. Documentación Automatizada en los medios informativos. Madrid: Paraninfo, 1987.

Gil Pechuán, Ignacio. Sistemas y Tecnologías de la Información para la Gestión. Madrid [etc]: Mcgraw-Hill, 1997.

Hidalgo Goyanes, Paloma (2003). "La selección de documentos audiovisuales en televisión: la selección en TVE”. En: Documentación de las Ciencias de la Información. Madrid: Universidad Complutense.

López Yepes, A. Documentación Informativa: Sistemas, redes y aplicaciones. Madrid: Síntesis, 1997

López Yepes, A. Documentación multimedia: el tratamiento automatizado de la información periodística, audiovisual y publicitaria. Salamanca: Universidad Pontificia, 1993. 
Muñoz Cruz, Valle. Gestión y Planificación de sistemas y servicios de información. En: Introducción a la Documentación Informativa y Periodística. Sevilla: MAD, 1999.

Ros García, J. Los sistemas y las redes de información y documentación. En: Manual de Información y Documentación. Madrid: Pirámide, 1996, p. 115.

Valle Gastaminza, Félix del. La documentación de los medios informativos. En: Manual de Periodismo. Barcelona: Ed. Prensa Ibérica, 1995, p. 61-83

Valle Gastaminza, Félix del. Proyecto docente de Documentación General e Informativa. Madrid: Facultad de Ciencias de la Información, Universidad Complutense, 1991. 